\title{
Organizadoras
}

Francisca Joyce Elmiro Timbó Andrade

Georgia Maciel Dias de Moraes

Herlene Greyce da Silveira Queiroz

\section{Gestão da Qualidade e Segurança dos Alimentos Coletânea de Pesquisas Acadêmicas}

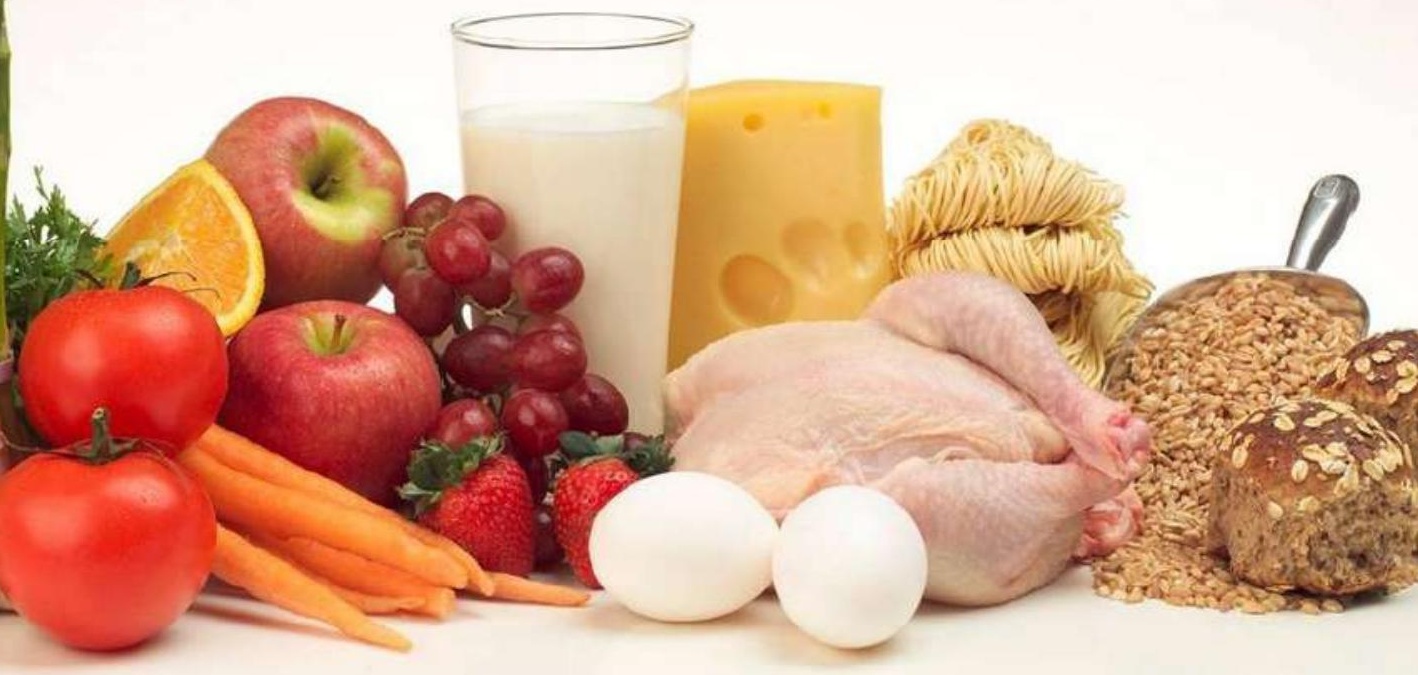


Francisca Joyce Elmiro Timbó Andrade Doutora em Biotecnologia Industrial - RENORBIO - UFPE, Mestre em Ciências da Educação pela Universidade Lusófona-Portugal, Especialização em Meio Ambiente, direcionado a Alimentos Orgânicos, graduação em Tecnologia de Alimentos pelo Instituto Centro de Ensino Tecnológico-CENTEC e graduação em Curso Especial de

Formação Pedagógica pela Universidade Estadual Vale do Acaraú. Atualmente é professora do Instituto Federal de Educação, Ciência e Tecnologia do Ceará-IFCE Campus de Sobral, no Eixo Tecnológico de Produção Alimentícia. Tem experiência na área de Ciência e Tecnologia de Alimentos, com ênfase em Panifícios, Avaliação e Controle de Qualidade de Alimentos, polissacarídeos (extração, isolamento e aplicação na área alimentar).

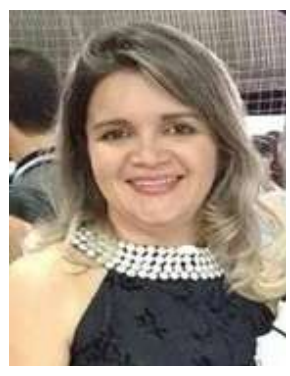

Georgia Maciel Dias de Moraes

Doutora em Biotecnologia, Mestre em Ciência e Tecnologia de Alimentos pela Universidade Federal da Paraíba, Especialista em Meio Ambiente, possui graduação em Tecnologia de Alimentos pelo Instituto Centro de Ensino Tecnológico (2001) e graduação em Curso Especial de Formação Pedagógica com habilitação em Biologia pela Universidade Estadual Vale do Acaraú (2003). Atualmente é Professora do Instituto Federal de Educação Ciência e Tecnologia do Ceará-IFCE Campus Sobral. Tem experiência na área de Ciência e Tecnologia de Alimentos, com ênfase em Análise Sensorial e Avaliação e Controle de Qualidade de Alimentos e Composição Química dos Alimentos.

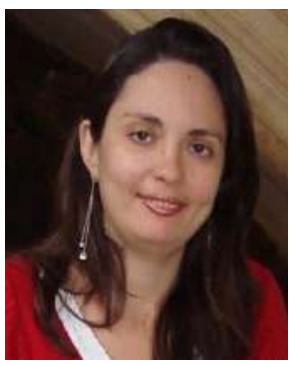

Herlene Greyce da Silveira Queiroz

Possui Graduação em Engenharia de Alimentos pela Universidade Federal do Ceará (2004), Mestrado em Tecnologia de Alimentos pela Universidade Federal do Ceará (2007) e Doutorado em Ciência e Tecnologia de Alimentos pela Universidade Federal do Ceará (2016).

Atualmente é professora do Instituto Federal de Educação, Ciência e Tecnologia do Ceará - Campus Sobral. Tem experiência na área de Ciência e Tecnologia de Alimentos, com ênfase em Desenvolvimento de Novos Produtos, Análise Sensorial e Avaliação e Controle de Qua-

lidade de Alimentos, atuando principalmente nos seguintes temas: Desenvolvimento de Novos Produtos, Avaliação Sensorial, Controle de Qualidade de Alimentos.

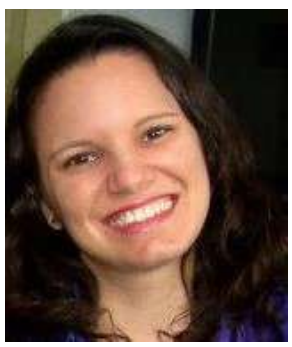




\section{Organizadoras}

Francisca Joyce Elmiro Timbó Andrade

Georgia Maciel Dias de Moraes

Herlene Greyce da Silveira Queiroz

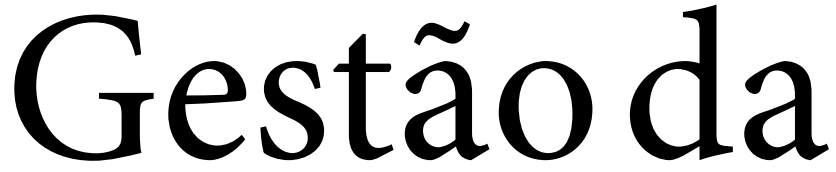

Qualidade e Segurança

dos Alimentos

Coletânea de Pesquisas Acadêmicas

Sobral/CE

2020

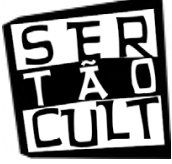


Gestão da Qualidade e Segurança dos Alimentos: Coletânea de Pesquisas Acadêmicas

(C) 2020 copyright by Francisca Joyce Elmiro Timbó Andrade, Georgia Maciel Dias de Moraes e Herlene Greyce da Silveira Queiroz (Orgs.) Impresso no Brasil/Printed in Brasil

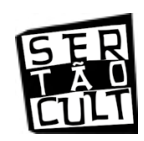

Rua Maria da Conceição P. de Azevedo, 1138

Renato Parente - Sobral - CE

(88) 3614.8748 / Celular (88) 99784.2222

contato@editorasertaocult.com

sertaocult@gmail.com

www.editorasertaocult.com

\section{Coordenação do Conselho Editorial}

Antonio Jerfson Lins de Freitas

\section{Conselho Editorial}

Ciências Agrárias, Biológicas e da Saúde

Aline Costa Silva

Carlos Eliardo Barros Cavalcante

Cristiane da Silva Monte

Francisco Ricardo Miranda Pinto

Janaína Maria Martins Vieira

Maria Flávia Azevedo da Penha

Percy Antonio Galimbertti

Vanderson da Silva Costa

\section{Coordenação Editorial e Projeto Gráfico}

Marco Antonio Machado

Revisão

Danilo Barahuna

\section{Catalogação}

Leolgh Lima da Silva - CRB3/967

Série

Alimento

G393 Gestão da qualidade e segurança dos alimentos: coletânea de pesquisas acadêmicas. / Francisca Joyce Elmiro Timbó Andrade, Georgia Maciel Dias de Moraes, Herlene Greyce da Silveira Queiroz. (Orgs.). Sobral CE: Sertãocult, 2020. $222 \mathrm{p}$.

ISBN: 978-65-87429-01-4 - papel

Número ISBN: 978-65-87429-00-7 - E-book-pdf

Doi: $10.35260 / 87429007-2020$

1. Gestão de alimentos- Qualidade. 2. Segurança alimentar. 3. Pesquisas acadêmicas- Gestão e segurança alimentar. I. Título. II. Andrade, Francisca Joyce Elmiro Timbó. III. Moraes, Georgia Maciel Dias de. IV. Queiroz, Herlene Greyce da Silveira. 


\section{APRESENTAÇÃO}

Criado em 2015 com o objetivo de capacitar profissionais para atuar na gestão e segurança dos alimentos em diferentes estabelecimentos de manipulação, produção e/ou comercialização de alimentos, o Curso de Especialização em Gestão da Qualidade e Segurança dos Alimentos ofertou a sua primeira turma no semestre 2016.2, no Instituto Federal do Ceará Campus de Sobral. Esse livro, intitulado “Gestão da Qualidade e Segurança dos Alimentos”, é fruto das pesquisas de quinze estudantes dessa primeira turma da especialização. Tendo cada capítulo o artigo da pesquisa desses estudantes e seus colaboradores.

Doze capítulos foram desenvolvidos, tendo como objeto de estudo o ambiente, o proprietário ou o usuário de locais de manipulação, processamento e/ ou comercialização de alimentos, como unidades de alimentação e nutrição de escolas (relatados nos capítulos 1, 6, 5, 7 e 10 do livro), restaurantes e padarias (apresentados em dois capítulos cada um, capítulos 2 e 9 e capítulos 11 e 14, respectivamente), unidade de alimentação hospitalar, cafeteria e supermercado (descritos nos capítulos 3, 4 e 8, respectivamente); dois capítulos tiveram como objeto de estudo processos da indústria de panifícios (capítulos 12 e 13) e o último capítulo (15) trata de uma análise de conteúdo de livros.

Seis capítulos tratam de aspectos de adequação a legislação, sendo três com foco em unidades de alimentação de escolares: dois capítulos baseados nas Resoluções - RDC no 275/2002 e 216/2004 do Ministério da Saúde/Anvisa (capítulos: 1 e 5) e o capítulo 2 baseado no checklist, extraído da base de dados do Fundo Nacional de Desenvolvimento da Educação (FNDE) Ministério da Educação - PNAE (Programa Nacional de Alimentação Escolar); um em restaurante baseado na Portaria de Centro de Vigilância Sanitária n ${ }^{\circ}$. 5/2013 - o capítulo 2; um com foco em uma unidade de alimentação hospitalar baseado na RDC no 275/2002 do Ministério da Saúde/Anvisa - capítulo 3; e o capitulo 
4, baseado na RDC no 216/2004 do Ministério da Saúde/Anvisa, estudo esse realizado em uma cafeteria.

O capítulo 7 aplica ferramentas da qualidade no controle do desperdício em uma unidade de Alimentação e Nutrição que funciona como terceirizada em uma escola profissionalizante. O capítulo 8 avalia o perfil de consumidores de produtos orgânicos, e três outros capítulos são de estudos baseados em pesquisa de opinião, sendo eles: o capítulo 9, que avalia a satisfação de clientes de restaurantes; o capítulo 10, que descreve os estudos da avaliação da preferencia da merenda escolar, e o capítulo 11, que descreve o estudo da percepção dos empresários de panificadoras sobre a implantação das boas práticas de fabricação.

Os capítulos 12, 13 e 14 descrevem melhorias de processos, sendo eles: Influência do método de processamento das matérias-primas e aditivos na produção de biscoitos wafer; Aumento da produtividade de biscoito cream cracker através de melhoria de processo e Implantação de calendários de produção e da tecnologia de congelamento em uma padaria, respectivamente.

O capítulo 15 descreve a análise de conteúdo dos livros de química do $3^{\circ}$ ano do ensino médio em relação à educação alimentar e nutricional.

$\mathrm{Na}$ certeza de que este livro contribuirá com a divulgação destas pesquisas e com a melhoria na qualidade e segurança dos alimentos servidos na região norte do Estado do Ceará, bem como com a educação e sensibilização sobre as legislações em serviços de alimentação, recomendo que seja lido pela população de maneira geral e, em especial, por todos que trabalham em serviços de alimentação.

Daniele Maria Alves Teixeira

Professora do Ensino básico, técnico e tecnológico do Instituto Federal do Ceará (IFCE). Dra. em Bioquímica. Professora da Especialização em Gestão da Qualidade e Segurança dos Alimentos e do Curso de Mestrado em Tecnologia de Alimentos do IFCE. Atua nas áreas de pesquisa: Química de Macromoléculas e Uso de polissacarídeos Vegetais em Alimentos. Coordenadora de pesquisa, pós graduação e Inovação do Campus Sobral de janeiro de 2015 até a presente data. 


\section{SUMÁRIO}

\section{CAPÍTULO 1 Doi: 10.35260/87429007.p.7-21.2020}

Aspectos higiênico-sanitários de unidade de alimentação e nutrição de escolas públicas da rede estadual / 7

\section{CAPÍTULO 2 Doi: 10.35260/87429007.p.23-36.2020}

Avaliação das condições higiênico-sanitárias de serviços de alimentação através da portaria Centro de Vigilância Sanitária N ${ }^{\circ}$. 5/2013: um estudo descritivo / 23

\section{CAPÍTULO 3 Doi: 10.35260/87429007.p.37-49.2020}

Boas práticas de manipulação em uma unidade de alimentação e nutrição hospitalar de uma cidade da região noroeste do Ceará / 37

\section{CAPÍTULO 4 Doi: 10.35260/87429007.p.51-6.2020}

Boas práticas de fabricação de alimentos: avaliação do conhecimento dos manipuladores de uma cafeteria da cidade de Viçosa do Ceará-CE /51

\section{CAPÍTULO 5 Doi: 10.35260/87429007.p.63-73.2020}

Verificação das boas práticas no preparo da merenda escolar em uma creche na cidade de Cruz-CE / 63

CAPÍTULO 6 Doi: 10.35260/87429007.p.75-86.2020

Avaliação das condições higiênico-sanitárias e das boas práticas de manipulação de alimentos na produção da merenda escolar de crianças do ensino fundamental em escolas municipais em Morrinhos-CE / 75

CAPÍTULO 7 Doi: 10.35260/87429007.p.87-99.2020

Aplicação do diagrama de causa e efeito na análise do resto ingesta per capta para avaliação e controle do desperdício em uma UAN escolar no município de Santana do Acaraú-CE / 87 
CAPÍTULO 8 Doi: 10.35260/87429007.p.101-118.2020

Análise do perfil de compra e consumo de produtos orgânicos em Sobral-CE / 101

CAPÍTULO 9 Doi: 10.35260/87429007.p.119-131.2020

Avaliação da satisfação dos clientes dos serviços de restaurantes da cidade de Tianguá-CE: uma análise descritiva / 119

CAPÍTULO 10 Doi: 10.35260/87429007.p.133-143.2020

Perfil de preferência da merenda escolar em uma escola estadual de educação profissionalizante na cidade de Sobral-CE / 133

CAPÍTULO 11 Doi: 10.35260/87429007.p.145-163.2020

A percepção dos empresários das micro e pequenas panificadoras da cidade de Sobral sobre a implantação das boas práticas de fabricação / 145

CAPÍTULO 12 Doi: 10.35260/87429007.p.165-173.2020

Influência do método de processamento das matérias-primas e aditivos na produção de biscoitos wafer / 165

CAPÍTULO 13 Doi: 10.35260/87429007.p.175-189.2020

Aumento da produtividade de biscoito cream cracker através de melhoria no processo em uma indústria alimentícia / 175

CAPÍTULO 14 Doi: 10.35260/87429007.p.191-199.2020

Implantação de calendários de produção e da tecnologia de congelamento em uma padaria: estudo de caso / 191

CAPÍTULO 15 Doi: 10.35260/87429007.p.201-221.2020

Educação alimentar e nutricional: análise de conteúdo dos livros de química do $3^{\circ}$ ano do ensino médio - PNLD - Triênio 2015-2017 / 201 


\section{CAPÍTULO 7}

Aplicação do diagrama de causa e efeito na análise do resto ingesta per capta para avaliação e controle do desperdício em uma UAN escolar no município de Santana do Acaraú-CE

Nara Nádja Severiano de Oliveira ${ }^{1}$ Herlene Greyce da Silva Queiroz ${ }^{2}$ Paolo Germano Lima de Araújo ${ }^{2}$ Érika Taciana Santana Ribeiro ${ }^{3}$

\section{INTRODUÇÃO}

UAN's são Unidades de Alimentação e Nutrição que trabalham com produção e distribuição de alimentos para coletividades, tendo como prioridade servir refeições saudáveis, com padrão higiênico sanitário, buscando atender às necessidades de seus clientes (SCHMIDT, 2014).

Sabe-se que o desperdício alimentar está incorporado à cultura brasileira, que é influenciado por diversos fatores, está presente em toda a cadeia produtiva até a distribuição. Segundo dados da Organização das Nações Unidas, o Brasil joga no lixo 30\% de tudo que produz, isto é, 160 bilhões de dólares por ano, montante que poderia amenizar a fome de mais de oito milhões de famílias. Os restaurantes que utilizam a modalidade de serviços a self service, ou seja, o cliente se serve à vontade, são os responsáveis pela maior quantidade de sobras de alimentos pós-consumo (AMORIM, 2010).

Neste contexto, é necessário que as unidades produtoras de refeições se ajustem, adotando práticas que preservem os recursos naturais e diminuam os danos ao ambiente (BARTHICHOTO et al., 2013).

Segundo Augustini et al. (2008), o controle de restos é mais difícil de ser realizado do que o controle de sobras limpas, pois englobam o cliente e sua relação com o produto, ambos fatores que variam diariamente. Medidas como campanhas voltadas aos clientes para que controlem seus restos e os conscientizem de que eles fazem parte do processo de redução do desperdício, alimen-

\footnotetext{
1 Discente do Curso de Pós-Graduação de Gestão da Qualidade e Segurança dos Alimentos - IFCE, Campus Sobral.

2 Docente do Instituto Federal de Educação, Ciência e Tecnologia do Ceará - IFCE, Campus Sobral Eixo de Produção Alimentícia.

3 Docente/Orientador do Instituto Federal de Educação, Ciência e Tecnologia do Ceará - IFCE, Campus Sobral - Eixo de Produção Alimentícia - E-mail: etaciana.ribeiro@gmail.com
} 
tos com propriedades organolépticas aceitáveis e a criação de condições para que o cliente possa, quando permitido em contrato, servir-se outra vez, são medidas que podem ajudar na redução de restos.

De acordo com Schmidt (2014), o desperdício mostra-se bastante significativo na produção de alimentos, o que pode indicar falta de comprometimento da equipe e dos clientes da UAN com a sua cidadania. Para Gomes e Jorge (2012), o resto-ingestão per capta é a relação entre o resto devolvido no prato pelo comensal e o número de refeições distribuídas. Conforme Carneiro (2015), alguns autores admitem como usual as empresas possuírem um percentual de restos entre $2 \%$ e $5 \%$ da quantidade servida ou de 15 a 45 gramas por pessoa, mas outros autores discordam, recomendando que o resto deva ser próximo do zero. Para Vaz (2006), são aceitáveis percentuais inferiores a 3\% e $10 \%$ e sobras abaixo de $45 \mathrm{~g}$.

O controle de qualidade tem papel fundamental na redução do desperdício e na garantia da segurança dos consumidores ao adquirirem seus produtos. Sua aplicação guia toda empresa que busca melhoria contínua. Para tanto, faz-se necessário o uso de métodos e ferramentas para auxiliar nessa busca (GADELHA; MORAIS, 2015).

O Diagrama de Causa e Efeito ou Diagrama de Peixe ou de Ishikawa, é uma ferramenta da qualidade proposta por Ishikawa (1943), que tem como objetivo a análise das operações dos processos produtivos, relacionando um efeito e as possíveis causas que estão contribuindo para que ele ocorra (CARVALHO; PALADINI, 2012). A ferramenta é composta por flechas que apontam para as possíveis causas e são separadas por níveis. Há seis critérios comumente utilizados para o diagrama de causa e efeito: mão de obra, método, materiais, meio ambiente, máquinas e medição (GIACON; GASQUES, 2018).

Fornari Junior (2010), ao aplicar ferramentas da qualidade, entre elas o diagrama de Ishikawa, conseguiu resultados satisfatórios, possibilitando conhecer as principais causas que levavam ao acúmulo de resíduo de coco e assim a ações a serem tomadas perante esta situação. Vicenzi e Antoni (2017) conseguiram benefícios que estimularam os gerentes de produção e qualidade a desenvolverem projetos de melhoria junto aos líderes de setores de uma pequena indústria de alimentos. Lustosa e Loseski (2016) conseguiram reduzir em 28\% o número de reclamações via serviço de atendimento ao consumidor de um laticínio, sendo que a meta inicial era de $10 \%$, ou seja, os resultados foram superados. Giacon e Gasques (2018) conseguiram reduzir a geração de resíduos orgânicos em um restaurante universitário conforme foram constatados os possíveis pontos de melhoria. 
Considerando-se a quantidade de resíduo alimentar produzido no Brasil e a contribuição das UAN's neste cenário, este trabalho teve como objetivo avaliar esse desperdício através do resto ingesta per capta de uma Unidade de Alimentação e Nutrição escolar, assim como levantar hipóteses sobre as causas fundamentais deste desperdício utilizando ferramentas de controle de qualidade como o Diagrama de Ishikawa, além de sugerir ações que auxiliem na redução dessas perdas de alimentos na unidade estudada.

\section{METODOLOGIA}

Este estudo do tipo transversal com caráter quantitativo foi desenvolvido em uma Unidade de Alimentação e Nutrição que funciona como terceirizada em uma escola profissionalizante no município de Santana do Acaraú-CE.

A unidade atende estudantes com idade entre 14 a 21 anos, oferecendo aos seus comensais lanche da manhã, almoço e lanche da tarde, servindo, em média, 415 refeições em cada serviço, de segunda a sexta-feira. No almoço, o serviço é do tipo self service, exceto o prato protéico (120g). No cardápio é disponibilizada uma opção de carne, arroz, macarrão, feijão, um tipo de salada, sobremesa e suco. Os dados foram coletados entre os meses de outubro e novembro de 2017. Nesse período, foram realizadas visitas à cozinha da UAN e observada a distribuição do almoço.

Para avaliar e quantificar o desperdício, foi pesada, durante esse período, a lixeira situada na área de devolução de utensílios que continham os alimentos desprezados pelos comensais, descontando-se o peso da lixeira. As pesagens foram realizadas após o almoço por um aluno já treinado para este serviço, com o auxílio de uma balança digital portátil de marca TIAN com capacidade máxima de $150 \mathrm{~kg}$ e carga mínima de $0,1 \mathrm{~kg}$. O desperdício foi analisado de acordo com o cardápio servido.

Para fins de cálculo, utilizou-se a fórmula do desperdício diário citada por Vaz (2006), onde Resto Ingesta Per Capta = quantidade restos de alimentos desprezados/numero de refeições servidas.

Para identificar as causas que contribuíram para o desperdício, utilizou-se o diagrama de Ishikawa, na qual para a sua produção foi usada a técnica de "brainstorming", com a participação dos estudantes no levantamento de hipóteses das possíveis causas que resultaram nas perdas identificadas.

Na segunda semana do mês de outubro, iniciou-se uma campanha para sensibilizar os alunos quanto ao consumo consciente que contou com a colaboração de um grupo de estudantes da escola, o que permitiu uma melhor dis- 
seminação desta ideia entre eles. Utilizou-se como instrumento para sensibilização dos comensais a fixação de cartazes e banners educativos no refeitório, além de contar com o apoio da gestão escolar e líderes de sala na disseminação e divulgação da informação. Foram estabelecidas pela escola metas máximas de resto de alimentos até o mês de novembro de $15 \mathrm{~g}$ por pessoa e o objetivo seria alcançar resto zero.

O banco de dados do estudo foi tabulado através de uma planilha no programa Excel do Windows 95 e computados em tabelas para posterior análise.

\section{RESULTADOS E DISCUSSÕES}

A tabela 1 apresenta os valores médios semanais obtidos no mês outubro a novembro de 2017, com exceção dos sábados, domingos e feriados.

Tabela 1: Média dos resultados das pesagens de resto e per capita do resto de acordo com o $\mathrm{n}^{\circ}$ de refeições

\begin{tabular}{l|c|c|c}
\hline Período & Refeições $\left(\mathrm{n}^{\circ}\right)$ & Resto $(\mathrm{kg})$ & Resto ingesta per capita $(\mathrm{g})$ \\
\hline $1^{\text {a }}$ semana & 394 & 13,54 & 34 \\
\hline $2^{\text {a }}$ semana & 390 & 9,06 & 23 \\
\hline $3^{\text {a }}$ semana & 405 & 14,54 & 35 \\
\hline $4^{\text {a }}$ semana & 402 & 12,44 & 30 \\
\hline Média & 398 & 12,39 & 30 \\
\hline
\end{tabular}

Fonte: Autores, 2018.

De acordo com a tabela 1, observa-se que a UAN estudada apresenta uma média de resto por aluno variando entre $23 \mathrm{~g}$ a $35 \mathrm{~g}$ por pessoa. Foram jogados no lixo no período validado $230 \mathrm{~kg}$ de alimentos provenientes dos pratos dos comensais.

Os custos do desperdício têm impacto econômico, ambiental, social, ético e nutricional, pois é gasto dinheiro no consumo de energia, na aquisição, no transporte, armazenamento, distribuição, preparação dos alimentos, como também no tratamento e eliminação dos resíduos alimentares. Representa uma perda significativa ao longo da cadeia de abastecimento alimentar, pois recursos como o solo, energia e água devem ser aplicados de forma eficiente e sustentável, uma vez que são limitados (REMINI, 2018). Além das consequências econômicas e ambientais citadas, a diminuição dos índices representa um passo importante para combater a fome no mundo, como também contribui para a melhoria do estado nutricional da população.

Acioly et al. (2014) executaram um estudo em uma UAN durante seis dias, onde encontraram uma média per capta da unidade de $630 \mathrm{~g}$ e $30,8 \mathrm{~kg}$ de restos, que poderiam alimentar aproximadamente 52 pessoas. Prevendo que em 
um ano o desperdício de alimentos da unidade estudada equivaleria a mais de 1 tonelada de lixo $(1.884,61 \mathrm{~kg})$, onde essa quantidade de alimentos seria o suficiente para alimentar o equivalente a 2.991 pessoas neste período.

Abreu et al. (2012) encontraram valores de resto ingesta per capita oscilando entre $34 \mathrm{~g}$ e 123g, com média de 72g. Rabelo e Alves (2016) analisaram durante 30 dias uma unidade de alimentação institucional e encontraram uma média de $134,59 \mathrm{~g}$ de restos por pessoa.

Em um estudo realizado durante 14 dias por Augustini et al. (2008), foram encontrados valores de resto por cliente que manteve-se entre $40 \mathrm{~g}$ e $90 \mathrm{~g}$. Os autores destacam que os registros encontrados poderão servir como subsídio para a implantação de medidas de redução de desperdício e otimização da produtividade, pois a observação diária e a implantação de campanha de orientação, através da educação dos clientes e colaboradores, tornam possível a diminuição da taxa diária de resto-ingestão.

Em estudo realizado em um restaurante universitário, Zimmermann e Mesquita (2011) encontraram valores muito altos, onde a quantidade per capita de resto ingesta era de 141g, superiores aos encontrados neste estudo.

Os resultados expostos na tabela 1 demonstram redução do resto ingesta per capta na $2^{\mathrm{a}}$ semana, que pode ser justificada pela melhor apresentação do cardápio e a contribuição das ações da campanha contra o desperdício realizada pela escola, obtendo uma média de resto de $23 \mathrm{~g}$ por pessoa, alcançando valores próximos à meta inicial estipulada de $15 \mathrm{~g}$.

Destaca-se que a média do peso do resto passou de $13,54 \mathrm{~kg}$ na primeira semana de avaliação do resto para $9,06 \mathrm{~kg}$ durante a segunda semana de avaliação, o que representa uma redução de $33,08 \%$.

Carneiro (2015) identificou valores de $122 \mathrm{~g}$ de resto per capita por cliente antes do desenvolvimento de campanha contra o desperdício de alimentos em uma UAN localizada em uma universidade no estado de Goiás.

Silva et al. (2010) conseguiram redução nos valores do resto ingesta per capita durante intervenção educacional, ficando entre 21,1g e 30,6g, concordando com a literatura, que menciona que a observação diária e a implantação de campanha de orientação, através da educação dos clientes e colaboradores, tornam possível a diminuição da taxa diária de RI (AUGUSTINI et al., 2008).

De forma semelhante, Carneiro (2015) também encontrou resultados favoráveis ao realizar uma campanha contra o desperdício de alimentos em uma UAN no estado de Goiás, alcançando uma redução de $42 \%$ no resto total desprezado. 
Na campanha realizada por Zimmermann e Mesquita (2011), observaram uma redução nos restos após a primeira edição do resto zero, gerando uma redução significativa nos desperdícios de alimentos. Além disso, a porção consumida pelo cliente aumentou na primeira campanha, mantendo-se constante, demonstrando que a economia gerada pela redução no desperdício de alimentos não provocou prejuízos ao usuário.

Estudar o desperdício em uma UAN significa que a gestão preocupa-se com a avaliação dos seus serviços, esta avaliação deve ser entendida como uma estratégia na tomada de decisões para enfrentar e resolver os problemas dentro da unidade (SCHMIDT, 2014).

Avaliar e acompanhar o serviço oferecido pelos funcionários é importante, pois permite conhecer melhor a qualidade total dos serviços, possibilitando buscar formas e ferramentas para melhoria e seu comprometimento (FEIL; BOSCO; FASSINA, 2018).

A Figura 1 apresenta o diagrama obtido tendo como efeito o desperdício de alimentos em uma UAN terceirizada em uma Escola Profissional.

Figura 1

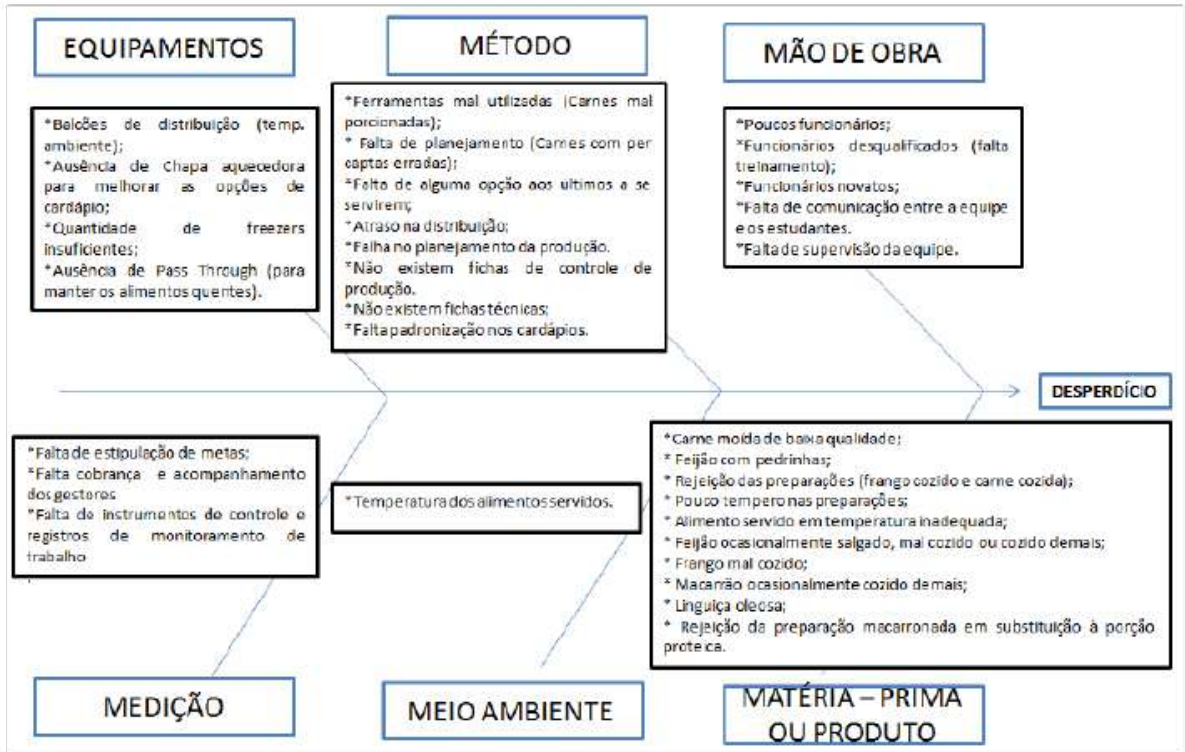

Fonte: Autores, 2018.

De acordo com o diagrama de Ishikawa apresentado, observaram-se as possíveis causas do desperdício de alimentos nas operações do processo produtivo.

A partir da análise do diagrama, foram elaboradas propostas de ações para os problemas identificados a serem aplicadas na UAN estudada visando dimi- 
nuir o desperdício de alimentos. A tabela 2 apresenta essas hipóteses levantadas dos possíveis problemas que contribuem para o desperdício e as ações sugeridas para a UAN. Vale ressaltar a importância destas e de outras ações para garantir a satisfação do cliente quanto ao serviço prestado pela empresa e na otimização do resto zero.

Tabela 2 - Levantamento de hipóteses sobre as causas fundamentais do desperdício e sugestões de ações corretivas

\begin{tabular}{|c|c|c|}
\hline ETAPAS & $\begin{array}{l}\text { HIPÓTESES/PROBLE- } \\
\text { MA }\end{array}$ & SUGESTÕES/SOLUÇÕES \\
\hline MÃO DE OBRA & $\begin{array}{l}\text { Poucos funcionários; } \\
\text { Falta treinamento. }\end{array}$ & $\begin{array}{l}\text { - Contratação de mais colaboradores; } \\
\text { - Capacitação da equipe periodicamente; }\end{array}$ \\
\hline MÉTODO & $\begin{array}{l}\text { Falta padronização nos } \\
\text { processos (per captas e } \\
\text { cardápios). }\end{array}$ & $\begin{array}{l}\text { - Criar planilhas para registro dos processos necessá- } \\
\text { rios; } \\
\text { - Realizar pesagens de uma amostragem de carnes } \\
\text { para verificar se os cortes estão com as per captas cor- } \\
\text { retas; } \\
\text { - Executar treinamento de funcionários em técnica } \\
\text { de padronização de cortes e distribuição da porção } \\
\text { protéica. } \\
\text { - Verificar o estoque diariamente para que o cardá- } \\
\text { pio planejado seja seguido. Em caso de mudança por } \\
\text { motivos maiores, avisar com antecedência a direção } \\
\text { da escola, contribuindo dessa forma para diminuir a } \\
\text { insatisfação dos clientes e descontrole da produção. }\end{array}$ \\
\hline MATÉRIA-PRIMA & $\begin{array}{l}\text { Baixa qualidade de ma- } \\
\text { térias-primas e produtos. }\end{array}$ & $\begin{array}{l}\text { - Melhorar o sabor, cortes e apresentação dos cardá- } \\
\text { pios com baixa aceitabilidade, como carne moída, } \\
\text { frango cozido e linguiça e verificar aceitabilidade após } \\
\text { a mudança nas preparações. } \\
\text { - Melhorar o sabor das preparações acrescentando } \\
\text { mais temperos naturais, verduras e legumes. } \\
\text { - Atentar-se ao ponto de cozimento dos alimentos; } \\
\text { - Atentar-se ao ponto do sal nas preparações; } \\
\text { - Melhorar a catação do feijão; } \\
\text { - Diminuir preparações com frituras; } \\
\text { - Ao servir preparações fritas, diminuir o óleo aparen- } \\
\text { te na apresentação do cardápio; } \\
\text { - Fazer pesquisa de satisfação dos clientes. }\end{array}$ \\
\hline
\end{tabular}




\begin{tabular}{|c|c|c|}
\hline MEIO AMBIENTE & $\begin{array}{l}\text { - Temperatura dos ali- } \\
\text { mentos baixa. } \\
\text { - Ao medir a temperatura } \\
\text { dos alimentos durante a } \\
\text { distribuição, as prepara- } \\
\text { ções do dia como, arroz, } \\
\text { apresentou temperatura } \\
\text { de } 41^{\circ} \mathrm{C} \text {, farofa } 33^{\circ} \mathrm{C} \text {, } \\
\text { Carne } 41^{\circ} \mathrm{C} \text { e feijão } 61^{\circ} \mathrm{C} \text {. }\end{array}$ & $\begin{array}{l}\text { - Seguir o preconizado pela RDC } 216 \text { de } 2004 \text {, na } \\
\text { etapa de distribuição dos alimentos, as preparações } \\
\text { quentes devem ser mantidas a temperatura maior que } \\
60^{\circ} \mathrm{C} \text { por no máximo } 6 \text { horas e as preparações frias } \\
\text { devem ser mantidas até } 10^{\circ} \mathrm{C} \text { por no máximo } 4 \text { horas. } \\
\text { - Aquisição de um Passthrough ou Banho Maria, visto } \\
\text { que a Unidade não possui tais equipamentos que con- } \\
\text { servam a temperatura dos alimentos; ou ligar o balcão } \\
\text { térmico. Na impossibilidade da compra de tais equi- } \\
\text { pamentos, planejar para que a produção fique pronta } \\
\text { próxima ao horário da distribuição. }\end{array}$ \\
\hline EQUIPAMENTOS & $\begin{array}{l}\text { - Poucos equipamentos } \\
\text { que inviabilizam a quali- } \\
\text { dade do serviço prestado. } \\
\text { Ausência de balanças; } \\
\text { - Ausência de termôme- } \\
\text { tro para alimentos; }\end{array}$ & $\begin{array}{l}\text { - Adquirir balanças para pesagens de alimentos e res- } \\
\text { tos; } \\
\text { - Adquirir termômetros para aferir temperaturas dos } \\
\text { alimentos; } \\
\text { - Implantação de câmaras de refrigeração ou aumen- } \\
\text { tar a quantidade de freezers, visto que a quantidade } \\
\text { desse equipamento é pequena e está sempre lotado, } \\
\text { o que compromete a qualidade dos alimentos, como } \\
\text { também, uma melhoria no planejamento e cumpri- } \\
\text { mento dos cardápios, essa falha pode ser consequên- } \\
\text { cia da falta de espaço que impede o armazenamento } \\
\text { de grandes volumes. }\end{array}$ \\
\hline MEDIÇÃO & $\begin{array}{l}\text { - Falta de instrumentos } \\
\text { de controle, registros e } \\
\text { monitoramento de pro- } \\
\text { dução; } \\
\text { - Ausência dos gestores } \\
\text { o que compromete a efi- } \\
\text { cácia na obtenção dos } \\
\text { resultados satisfatórios. }\end{array}$ & $\begin{array}{l}\text { - Verificar os restos desprezados pelos clientes diaria- } \\
\text { mente e avaliar o desperdício de acordo com o car- } \\
\text { dápio do dia; } \\
\text { - Ter o controle de todos os desperdícios de alimentos. } \\
\text { - Criar planilhas para registrar as quantidades que fo- } \\
\text { ram produzidas no dia, sobras do balcão de distribui- } \\
\text { ção e restos dos pratos dos clientes; } \\
\text { - Melhorar o acompanhamento e cobrança, estabele- } \\
\text { cendo metas juntos com a equipe o que contribui na } \\
\text { obtenção de resultados satisfatórios; } \\
\text { - Nutricionista visitar a unidade semanalmente e não } \\
\text { quinzenalmente; } \\
\text {-Delegar atribuições aos funcionários quanto aos no- } \\
\text { vos instrumentos de controle. }\end{array}$ \\
\hline
\end{tabular}

Fonte: Autores, 2018.

Observou-se a ausência de padronização nos processos, como per captas, controle de registros de produção e planejamento de cardápios, que foram identificados como geradores de desperdício, visto que as carnes servidas nem sempre seguiam a per capta estipulada pela empresa e a contratante. Além do cardápio planejado nem sempre ser seguido, o que pode contribuir para a insatisfação dos clientes e descontrole da produção.

O desperdício é sinônimo de baixa qualidade, algumas medidas para evitá-lo são: o planejamento do número de refeições, quantidades per capita, controle na distribuição do alimento, avaliação do rendimento da matéria-prima, 
elaboração de cardápios que satisfaçam os clientes, padronização de processos e serviços por meio da elaboração de rotinas e POP's, treinamento da equipe, monitoramento das atividades, através de checklist, conferência de temperaturas e equipamentos; e manutenção de registros (PARADA; OLIVEIRA, 2017; MOURA; HONAISER; BOLOGNINI, 2011; VAZ, 2006; ZANDONADI; MAURÍCIO, 2012).

Para Viana e Ferreira (2017), seria interessante a reavaliação de cardápios, substituindo preparações repetitivas, além de averiguar as preferências da clientela. Sendo necessário realizar constantemente estudos de forma a tentar sempre melhorar o atendimento.

Observou-se que a temperatura de alguns alimentos servidos estava abaixo do preconizado pela legislação. De acordo com a RDC 216 de 2004, na etapa de distribuição dos alimentos, as preparações quentes devem ser mantidas a temperatura maior que $60^{\circ} \mathrm{C}$ por no máximo 6 horas, e as preparações frias devem ser mantidas até $10^{\circ} \mathrm{C}$ por no máximo 4 horas.

Para Vasconcelos (2015), a satisfação dos clientes em Unidades de Alimentação e Nutrição é indispensável para o seu apropriado gerenciamento e sobrevivência. A avaliação de sobras e rejeitos alimentares são ações eficazes para avaliar o grau de satisfação do cliente, planejamento e execução adequada das preparações, além de contribuir no alcance e/ou projeção de meta para a UAN quanto à redução do desperdício de alimentos.

O hábito de desperdiçar, que na maioria das vezes não é consciente, foi o que mais contribuiu para a geração de restos. A escola atuou junto à empresa na conscientização dos alunos e funcionários, o que se mostrou eficaz no combate ao desperdício. Conforme Vaz (2006), Augustini et al. (2008) e Oliveira et al. (2015), para o controle dos restos alimentares é necessária a adoção de medidas como campanhas direcionadas aos clientes, conscientizando-os de que fazem parte do processo de redução de desperdício.

Com os dados provenientes desse estudo, torna-se possível implantar ações corretivas relacionadas ao ambiente interno da empresa, visando a redução do desperdício e, consequentemente, um processo mais eficaz para a empresa.

\section{CONCLUSÕES}

A análise do resto ingesta per capta e a realização do diagrama de Ishikawa possibilitaram quantificar o desperdício e propor ações que poderão contribuir em sua redução a valores próximos ao recomendado pela literatura. $\mathrm{O}$ ideal é zerar esse resto por uma questão não somente ética, mas econômica, política e social. 
A realização deste trabalho de forma contínua, com o acompanhamento do desperdício, com práticas educativas de conscientização dos usuários, incentivando-os à redução do desperdício de alimentos, engajamento e qualificação dos colaboradores, contribuirão na otimização da produtividade, atendendo assim às expectativas dos clientes e da empresa para qual presta serviço.

A aplicação da ferramenta permitiu observar que o desperdício quantificado e qualificado não é gerado apenas pelo cliente, mas sim, que pode estar relacionado a todos os quesitos apresentados no diagrama, desde o planejamento da produção, qualificação dos profissionais, elaboração de cardápios que satisfaçam os comensais, entre outros.

O diagrama de Ishikawa é uma excelente ferramenta da qualidade para guiar toda a empresa na melhoria contínua dos serviços ofertados, sua aplicação neste estudo permitiu uma visão geral das causas do desperdício, como também encontrar soluções para os problemas.

\section{REFERÊNCIAS BIBLIOGRÁFICAS}

ABREU, E. S.; SIMONY, R. F.; DIAS, D. H. S.; RIBEIRO, F. G. O. Avaliação do desperdíceo alimentar na produção e distribuição de refeições de um hospital de São Paulo. Revista Simbio-Logias, V.5, n.7, Dez/ 2012.

ACIOLY, P. L.; CLEMENTE, I. H.; AQUINO, G. R.V.; ZIMMERMANN, R. Avaliação do índice de resto-ingesta em uma Unidade de Alimentação e Nutrição (UAN) localizada na cidade de Antônio Carlos/ Santa Catarina. Disponível em: http://portal.estacio.br/media/4589590/avalia\%C3\%A7\%C3\%A3o\%20do\%20\%C3\%ADndice\%20de\%20restoingesta\%20 em\%20 uma\%20unidade\%20de\%20alimenta\%C3\%A7\%C3\%A3o\%20e\%20nutri\%C3\%A7\%C3\%A3o\%20(uan)\%20localizada\%20na\%20cidade\%20de.pdf. Acesso em: 14 de dez. de 2017.

AMORIM, K. N. Avaliação de resto-ingesta e sobras em unidades produtoras e refeições (UPRs) dos hotéis do município de Caruaru-PE. Trabalho de Conclusão de Curso- TCC, Caruaru: FAVIP, 25f. 2010.

AUGUSTINI, V. C. M.; KISHIMOTO, P; TESCARO, T. C.; ALMEIDA, F. Q. A Avaliação do índice de resto-ingesta e sobras em unidade de alimentação e nutrição (UAN) de uma empresa metalúrgica na cidade de Piracicaba / SP. Revista Simbio-Logias, Botucatu, v.1, n.1, p. 99-110, 2008.

BARTHICHOTO, M.; MATIAS, A. C. G.; SPINELLI, M. G. N.; ABREU, E. S. Responsabilidade ambiental: perfil das práticas de sustentabilidade desenvolvidas em unidades produtoras de refeições do bairro de Higienópolis, município de São Paulo. Qualitas Revista Eletrônica, v. 14, n. 1, 2013. ISSN 1677- 
4280. Disponível em: http://revista.uepb.edu.br/index.php/qualitas/article/ view/1680. Acesso em: 16 jan. 2019. doi: http://dx.doi.org/10.18391/qualitas. v14i1.1680.

BRASIL. Ministério da Saúde. Dispõe sobre regulamento técnico de boas práticas para serviços de alimentação. Resolução da Diretoria Colegiada n. 216, de 15 de setembro de 2004. Diário Oficial da União, Brasília, 16 de setembro de 2004 .

CARNEIRO, N.S. Desenvolvimento de campanha contra desperdício de alimentos em uma unidade de alimentação e nutrição na cidade de Mineiros Goiás. Rev. Saúde Multidisciplinar, Faculdade Mineirense - FAMA Mineiros/ GO - Vol. II, p. 19-29, mar. 2014. Disponível em: https://www.fampfaculdade. com.br/wp-content/uploads/2019/03/Art.-2-DESENVOLVIMENTO-DE-CAMPANHA-CONTRA-DESPERD\%C3\%8DCIO-DE-ALIMENTOS.pdf. Acesso em: 12 jan. 2019.

CARVALHO, M. M; PALADINI, E. P. Gestão da Qualidade: teoria e casos. 2 ${ }^{\mathrm{a}}$ edição. Elsevier, 2012. 456p.

FEIL, C. C.; DAL BOSCO, S. M.; FASSINA, P. Pesquisa de satisfação dos comensais de uma unidade de alimentação e nutrição. REVISTA UNINGÁ, v. 43, n. 1, 2018.

GADELHA, G. R. O; MORAIS, G. H. N. Análise do processo de desperdícios de embalagens em uma indústria alimentícia: Aplicação das quatro primeiras etapas do MASP. XXXV Encontro Nacional da Engenharia da Produção, Fortaleza, CE, Brasil, 2015.

GIACON, Joao Victor; GASQUES, Ana Carla Fernandes. Análise quantitativa de resíduos orgânicos: estudo de caso em um restaurante universitário. Trabalhos de Conclusão de Curso do DEP, v. 13, n. 1, 2018. Disponível em: http://www.dep.uem.br/gdct/index.php/dep_tcc/article/view/422. Acesso em: 17 jan. 2019.

GOMES, G. S.; JORGE, M. N. Avaliação do índice de resto-ingestão e sobras em uma unidadeprodutora de refeição comercial em Ipatinga-MG. Nutrir Gerais, Ipatinga, v. 6 n. 10, p. 857-868, fev./Jul. 2012.

FORNARI JUNIOR, C. C. M. Aplicação da ferramenta da qualidade (diagrama de Ishikawa) e do PDCA no desenvolvimento de pesquisa para a reutilização dos resíduos sólidos de coco verde. INGEPRO-Inovação, Gestão e Produção, v. 2, n. 09, 2010.

LUSTOSA, J. C.; LOZESKI, M. L. C. Implantação da metodologia PDCA em um laticínio para reduzir o número de reclamações via serviço de atendimento ao consumidor: um estudo de caso. 2016. Trabalho de Conclusão de Curso (Tecnologia em Alimentos). Universidade Tecnológica Federal do Paraná. 
MOURA, P. N.; HONAISER, A.; BOLOGNINI, M. C. M. Avaliação do índice de resto-ingesta e sobras em unidade de alimentação e nutrição (UAN) do Colégio Agrícola de Guarapuava/PR. Revista Salus, v. 3, n. 1, p. 71-77, 2011.

OLIVEIRA, A. M. A.; BENTO, J. C.;ESPINDOLA, N. S.; SANTOS, P. G.; PROVETTI, T. A. Aceitabilidade de cardápios oferecidos no restaurante popular João Domingos Fassarela do município de Governador Valadares- MG. Disponível em: http://www.pergamum.univale.br/pergamum/tcc/Aceitabilidadedecardapiosoferecidosnorestaurantepopularjoaodomingosfassareladomunicipiodegovernadorvaladaresmg.pdf. Acesso em: 15 de dez. de 2017.

PARADA, A. D.; OLIVEIRA, F. R. G. Desperdício alimentar: conscientização dos comensais de um serviço hospitalar de alimentação e nutrição. Arquivos de Ciências da Saúde, v. 24, n. 3, p. 61-64, 2017.

RABELO, N. M. L.; ALVES, T. C. U. Avaliação do percentual de resto-ingestão e sobra alimentar em uma unidade de alimentação e nutrição institucional. Revista brasileira tecnologia agroindustrial, Ponta Grossa, v.10. n.1.p.2039-2052. Jan./jun.2016. Disponível em: https://periodicos.utfpr.edu. br/rbta/article/viewFile/1808/3136. Acesso em: 20 de jan. 2018.

REMINI, Katy. Avaliação quantitativa do desperdício alimentar na Santa Casa da Misericórdia de Leiria. 2018. Tese de Doutorado. Universidade de Lisboa, Faculdade de Medicina Veterinária. Disponível em: https://www.repository.utl.pt/bitstream/10400.5/15007/1/Avalia\%C3\%A7\%C3\%A3o\%20quantitativa\%20do\%20desperd\%C3\%ADcio\%20alimentar\%20na\%20Santa\%20 Casa\%20da\%20Miseric\%C3\%B3rdia\%20de\%20Leiria.pdf. Acesso em:15 jun. 2018.

SCHMIDT, Vanessa. Análise do índice de resto-ingesta em uma unidade de alimentação e nutrição do Noroeste do Estado do Rio Grande do Sul. Trabalho de Conclusão de Curso (Nutrição) - Universidade Regional de Unjuí. Unijuí, RS. 2014. 20f. Disponível em: http://bibliodigital.unijui.edu.br:8080/ xmlui/handle/123456789/2582. Acesso em: 15 dez. 2017.

SILVA, A. M.; SILVA, C. P; PESSINA, E. L. Avaliação do índice de resto ingesta após campanha de conscientização dos clientes contra o desperdício de alimentos em um serviço de alimentação hospitalar. Revista Simbio-Logias, v. 3, n. 4, p. 43-56, 2010.

VASCONCELOS, M. P. N. Avaliação do resto-ingesta e sobras de alimentos em uma unidade de alimentação e nutrição de uma unidade socioeducativa localizada em Abreu e Lima Pernambuco. Monografia. (Especialista em Alimentação Coletiva) -Instituto Nacional de Eensino Superior e Pesquisa-INESP e Centro de Capacitação Educacional-CCE. Recife. 2015. Disponível em: http://ccecursos.com.br/img/resumos/avalia--o-do-resto-ingesta-e-sobras-de-alimentos-em-uma-unidade-socioeducativa-localizada-em-abreu-e-lima-pe.pdf. Acesso em: 10 maio 2018. 
VAZ, C. S. Restaurantes: controlando custos e aumentando lucros. Brasília: Metha Ltda. 196 p. 2006.

VIANA, R. M.; FERREIRA, L. C. Avaliação do desperdício de alimentos em uma unidade de alimentação e nutrição na cidade de Januária-MG. Revista Higiene Alimentar, p. 22-26, 2017.

VICENZI, J. B.; ANTONI, V. L. Obtendo produtividade com a aplicação do conceito de produção enxuta: o caso de uma pequena indústria de alimentos. Encontro de Estudos sobre Empreendedorismo e Gestão de Pequenas Empresas - IX EGEPE. Rio Grande do Sul, 2016. Disponível em: http://www.egepe. org.br/2016/artigos-egepe/449.pdf. Acesso em: 14 jun. 2018.

ZANDONADI, H. S.; MAURÍCIO, A. A. Avaliação do índice de resto-ingesta, de refeições consumidas por trabalhadores da construção civil no município de Cuiabá, MT. Revista Higiene Alimentar, São Paulo, v.26, n.206/207, p. 6470, 2012.

ZIMMERMANN A. M.; MESQUITA M. O. Campanha resto zero em restaurante universitário. Revista Disc. Scientia, Santa Maria; 12(1): 115-125. 2011. 